\title{
Gambaran Persepsi lbu Hamil Tentang Keamanan Obat Selama Kehamilan di UPT Puskesmas Puter Kota Bandung
}

\author{
D. A. A. Kurniasih*, C. S. Salasanti, L. Aprilia \\ Program Studi Farmasi, Akademi Farmasi YPF, Bandung \\ *Email korespondensi: deaariani@gmail.com \\ (Submit 15/03/2019, Revisi 05/09/2019, Diterima 20/12/2019)
}

\begin{abstract}
Abstrak
Selama masa kehamilan, ibu dan janin adalah unit fungsi yang tak terpisahkan. Survei WHO menunjukkan bahwa $86 \%$ wanita memperoleh obat-obatan selama kehamilan. Beberapa obat dapat melintasi plasenta sehingga dapat mempengaruhi janin. Oleh karena itu, penggunaan obat pada ibu hamil perlu mendapatkan perhatian. Penelitian ini bertujuan untuk mengetahui gambaran persepsi ibu hamil terhadap keamanan obatobatan selama kehamilan. Desain yang digunakan dalam penelitian ini adalah penelitian survey, yaitu data penelitian yang diambil populasi dengan menggunakan kuesioner sebagai alat pengumpul data yang pokok. Pengambilan data primer dilakukan secara cross sectional dengan skala Likert. Berdasarkan analisis Three Box Method, persepsi ibu hamil terhadap keamanan obat yang digunakan selama masa kehamilan berada dalam kategori sedang (baik).
\end{abstract}

Kata kunci: Persepsi, ibu hamil, keamanan obat

\section{Outline}

- Pendahuluan

- Metode

- Hasil dan Pembahasan

- Kesimpulan

- Ucapan Terima Kasih

- Daftar Pustaka

\section{Pendahuluan}

Selama kehamilan dan menyusui, seorang ibu dapat mengalami berbagai keluhan atau gangguan kesehatan yang membutuhkan obat. Banyak ibu hamil menggunakan obat dan suplemen pada periode organogenesis sedang berlangsung yang memungkinkan risiko terjadi cacat lahir janin lebih besar ${ }^{1}$. Dalam 30 tahun terakhir, jumlah wanita hamil yang mengkonsumsi obat-obatan telah meningkat lebih dari dua kali dengan rasio 9 dari 10 wanita menggunakan setidaknya mengkonsumsi satu obat selama kehamilan². Penggunaan obat selama kehamilan kemungkinan dapat menimbulkan efek yang merugikan baik untuk ibu maupun fetus.

Konsumsi obat-obatan saat kehamilan seharusnya dikontrol melalui supervisi dokter, dimana beberapa zat aktif ada kemungkinan untuk menembus plasenta dan 
berpengaruh pada pertumbuhan fetus ${ }^{3,4}$. Penggunaan obat baik yang diresepkan maupun obat bebas over the counter (OTC) digunakan oleh $88,8 \%$ wanita hamil di Amerika Serikat ${ }^{5}$. Di Eropa, Amerika Utara, Amerika Selatan dan Australia setidaknya 8 dari 10 wanita mengkonsumsi obat paling tidak satu macam baik obat resep maupun OTC 6 . Dari 216 obat yang diresepkan, suplemen besi merupakan obat yang paling banyak diresepkan dan diikuti dengan multivitamin dan asam folat ${ }^{7}$.

Tingkat pengetahuan ibu akan keamanan obat merupakan faktor yang penting untuk menjaga keselamatan bayi ${ }^{8}$. Lebih dari separuh responden (responden yang terlibat sebanyak 184) selalu mencari informasi mengenai keamanan produk yang akan dikomsumsi saat kehamilan ${ }^{9}$. Berdasarkan latar belakang tersebut, maka penelitian ini bertujuan untuk mengetahui gambaran Persepsi Ibu Hamil tentang Keamanan Obat Selama Kehamilan di UPT Puskesmas Puter Kota Bandung.

\section{Metode}

Penelitian ini merupakan penelitian deskriptif dengan pengumpulan data primer dilakukan menggunakan metode survey secara belah lintang. Sampel penelitian berjumlah 90 responden dimana pemilihan sampel dilakukan dengan metode purposif. Sampel penelitian harus memenuhi kriteria inklusi : ibu hamil yang melakukan pengobatan rawat jalan di UPT Puskesmas Puter Kota Bandung, bersedia menjadi responden dalam penelitian, dan bersedia melengkapi informed consent yang telah disediakan. Instrumen pengumpulan data yang digunakan adalah kuesioner dengan bentuk pertanyaan tertutup dengan format check list, dengan penilaian persepsi menggunakan skala Likert. Teknik skoring yang digunakan dalam penelitian ini adalah dengan menggunakan skor minimal 1 dan maksimal 5. Skor 1 berarti sangat tidak setuju, skor 2 berarti tidak setuju, skor 3 berarti netral, skor 4 berarti setuju dan skor 5 untuk sangat setuju. Angka jawaban responden akan disajikan kedalam bentuk nilai indeks skala 100 yang selanjutnya akan dibagi menggunakan kriteria 3 kotak (Three Box Method) yang berfungsi untuk mengelompokkan jawaban dari responden ${ }^{10}$.

Tabel 1. Three box method

\begin{tabular}{|c|c|c|}
\hline Rendah (Buruk) & Sedang (Baik) & Tinggi (Sangat Baik) \\
\hline $20,00 \%-46,56 \%$ & $46,67-73,33 \%$ & $73,34-100 \%$ \\
\hline
\end{tabular}

\section{Hasil dan Pembahasan}

Kuesioner sebagai instrument penelitian telah dilakukan analisis validitas dan reliabilitas dimana seluruh perolehan nilai koefisien validitas pada masing-masing atribut pengukur persepsi lebih tinggi dari batas toleransi 0,30 sehingga seluruh atribut adalah valid dalam mengukur variabelnya. Analisis reliabilitas dihitung menggunakan rumus AlphaCronbach dengan hasil variabel persepsi termasuk kategori reliabel, karena skornya > 0,700 .

Karakteristik responden pada pasien ibu hamil yang berkunjung ke UPT Puskesmas Puter Kota Bandung dapat dilihat pada Tabel 2. Mayoritas responden penelitian adalah ibu hamil dengan usia 20-25 tahun, masa kehamilan berada pada trimester III, bukan kehamilan pertama yaitu telah memiliki satu anak, tingkat pendidikan SMA, dengan pekerjaan lainnya, memiliki pengeluaran antara Rp1.000.000-Rp1.500.000 per bulan, dan memiliki penyakit saat kehamilan. 
Pada Tabel 3, persepsi ibu hamil terhadap 12 pernyataan pada kuesioner rata-rata berada pada kategori sedang (baik). Tiga (3) pernyataan dari dua belas (12) pernyataan pada kuesioner, persepsi ibu hamil berada dalam kategori tinggi (sangat baik), yaitu terdapat pada pernyataan "obat yang diberikan oleh dokter/bidan merupakan obat yang aman bagi kehamilan saya", "saya memerlukan informasi mengenai indeks obat-obatan kategori keamanan pada kehamilan", "saya membutuhkan bantuan untuk membantu menjelaskan istilah medis yang kurang saya pahami". Selain itu, pada Tabel 3 juga dapat dilihat nilai tanggapan seluruh responden terhadap 12 pernyataan memiliki skor sebesar 3.712 dengan persentase 68,74\%. Jika 68,74\% tersebut dikonversikan ke kategori nilai kualitatif maka persepsi ibu hamil tentang keamanan obat yang digunakan selama masa kehamilan di UPT Puskesmas Puter Kota Bandung berada dalam kategori sedang (baik).

Tabel 2. Karakteristik responden penelitian

\begin{tabular}{|c|c|c|c|}
\hline \multicolumn{2}{|l|}{ Karakteristik Responden } & Jumlah & $\%$ \\
\hline \multirow[t]{6}{*}{ Usia Ibu Hamil } & $<20$ tahun & 2 & 2 \\
\hline & 20 s.d 25 tahun & 37 & 41 \\
\hline & 25 s.d 30 tahun & 29 & 32 \\
\hline & 30 s.d 35 tahun & 13 & 14 \\
\hline & 35 s.d 40 tahun & 9 & 10 \\
\hline & $>40$ tahun & 0 & 0 \\
\hline \multirow[t]{3}{*}{ Usia Kehamilan } & Trimester I (0 s.d 12 minggu) & 10 & 11 \\
\hline & $\begin{array}{c}\text { Trimester II (13 s.d } 24 \\
\text { minggu) }\end{array}$ & 16 & 18 \\
\hline & $\begin{array}{l}\text { Trimester III ( } 25 \text { minggu - } \\
\text { kelahiran) }\end{array}$ & 64 & 71 \\
\hline \multirow[t]{6}{*}{ Jumlah Anak } & 0 & 24 & 27 \\
\hline & 1 & 36 & 40 \\
\hline & 2 & 20 & 22 \\
\hline & 3 & 9 & 10 \\
\hline & 4 & 1 & 1 \\
\hline & $>5$ & 0 & 0 \\
\hline \multirow[t]{6}{*}{ Pendidikan } & SD & 6 & 7 \\
\hline & SMP/Sederajat & 23 & 26 \\
\hline & SMA/Sederajat & 51 & 57 \\
\hline & Akademi & 2 & 2 \\
\hline & Perguruan Tinggi & 8 & 9 \\
\hline & Lainnya & 0 & 0 \\
\hline \multirow[t]{4}{*}{ Pekerjaan } & Pegawai Negeri Sipil & 0 & 0 \\
\hline & Karyawan Swasta & 20 & 22 \\
\hline & Wiraswasta & 9 & 10 \\
\hline & Lainnya & 61 & 68 \\
\hline \multirow[t]{4}{*}{ Pengeluaran per Bulan (Rp) } & $250.000-500.000$ & 2 & 2 \\
\hline & $500.000-1.000 .000$ & 14 & 16 \\
\hline & $1.000 .000-1.500 .000$ & 41 & 46 \\
\hline & $>1.500 .000$ & 33 & 37 \\
\hline \multirow[t]{2}{*}{ Penyakit saat Kehamilan } & Ya & 5 & 6 \\
\hline & Tidak & 85 & 94 \\
\hline
\end{tabular}

Penelitian ini membahas mengenai persepsi ibu hamil dimana instrumen yang digunakan adalah kuesioner yang telah diukur validitas dan reabilitasnya. Persepsi adalah suatu proses penginterpretasian terhadap stimulus atau rangsang yang diterima oleh individu ${ }^{11}$. Pengalaman dan informasi yang dimiliki seseorang merupakan faktor yang sangat berperan dalam menginterpretasikan stimulus yang diperoleh. Semakin 
banyak informasi dapat mempengaruhi atau menambah pengetahuan seseorang yang akhirnya seseorang akan berperilaku sesuai dengan pengetahuan yang dimiliki ${ }^{12}$. Hasil dari penelitian ini menunjukkan bahwa sebagian besar pendapat responden memiliki persepsi yang sedang (baik) terhadap keamanan penggunaan obat pada masa kehamilan. Hal tersebut dapat terjadi karena $73 \%$ responden telah memiliki pengalaman dan pengetahuan dari kehamilan sebelumnya (bukan hamil anak pertama). Dari Tabel 3, persepsi ibu hamil sangat baik terhadap pernyataan "obat yang diberikan oleh dokter/bidan merupakan obat yang aman bagi kehamilan saya". Hal tersebut dapat dikarenakan golongan obat yang terbanyak dikonsumsi oleh ibu hamil adalah vitamin dan mineral ${ }^{13}$. Persepsi ibu hamil sangat baik juga ditunjukkan terhadap pernyatan "saya memerlukan informasi mengenai indeks obat-obatan kategori keamanan pada kehamilan" dan "saya membutuhkan bantuan untuk membantu menjelaskan istilah medis yang kurang saya pahami". Hasil penelitian ini mendukung bahwa sumber informasi yang bisa diakses berasal dari dokter, brosur informasi obat dan apoteker ${ }^{14}$.

Tabel 3. Persepsi responden mengenai pernyataan pada kuesioner ibu hamil

\begin{tabular}{|c|c|c|c|c|c|c|c|c|}
\hline \multirow{2}{*}{ Pernyataan } & \multicolumn{5}{|c|}{ Frekuensi Skala Likert } & \multirow{2}{*}{ Skor } & \multirow{2}{*}{$\%$} & \multirow{2}{*}{ Kategori } \\
\hline & 1 & 2 & 3 & 4 & 5 & & & \\
\hline Tanpa obat saya akan menjadi sakit & 11 & 49 & 14 & 12 & 4 & 321 & 71,33 & $\begin{array}{l}\text { Sedang } \\
\text { (Baik) }\end{array}$ \\
\hline $\begin{array}{l}\text { Obat-obatan melindungi kehamilan saya } \\
\text { dari keadaan yang tidak saya inginkan }\end{array}$ & 4 & 9 & 31 & 35 & 11 & 310 & 68,89 & $\begin{array}{l}\text { Sedang } \\
\text { (Baik) }\end{array}$ \\
\hline $\begin{array}{l}\text { Saya merasa ragu untuk mengkonsumsi } \\
\text { obat saat kehamilan }\end{array}$ & 4 & 39 & 13 & 25 & 9 & 274 & 60,89 & $\begin{array}{l}\text { Sedang } \\
\text { (Baik) }\end{array}$ \\
\hline $\begin{array}{l}\text { Mengkonsumsi obat saat hamil membuat } \\
\text { saya khawatir }\end{array}$ & 4 & 45 & 9 & 24 & 8 & 283 & 62,89 & $\begin{array}{l}\text { Sedang } \\
\text { (Baik) }\end{array}$ \\
\hline $\begin{array}{l}\text { Terkadang saya khawatir terhadap efek } \\
\text { jangka panjang dari obat-obatan yang saya } \\
\text { konsumsi saat kehamilan }\end{array}$ & 2 & 16 & 29 & 33 & 10 & 303 & 67,33 & $\begin{array}{l}\text { Sedang } \\
\text { (Baik) }\end{array}$ \\
\hline $\begin{array}{l}\text { Obat-obatan saat kehamilan masih menjadi } \\
\text { misteri bagi saya }\end{array}$ & 2 & 35 & 28 & 21 & 4 & 280 & 62,22 & $\begin{array}{l}\text { Sedang } \\
\text { (Baik) }\end{array}$ \\
\hline $\begin{array}{l}\text { Terkadang saya khawatir menjadi orang } \\
\text { yang sangat mandiri terhadap obat-obatan } \\
\text { saat saya hamil }\end{array}$ & 7 & 21 & 26 & 30 & 6 & 263 & 58,44 & $\begin{array}{l}\text { Sedang } \\
\text { (Baik) }\end{array}$ \\
\hline $\begin{array}{l}\text { Obat yang diberikan oleh dokter/bidan } \\
\text { merupakan obat yang aman bagi kehamilan } \\
\text { saya }\end{array}$ & 0 & 3 & 8 & 56 & 23 & 369 & 82,00 & $\begin{array}{c}\text { Tinggi } \\
\text { (Sangat Baik) }\end{array}$ \\
\hline $\begin{array}{l}\text { Saya merasa beberapa obat dapat } \\
\text { berbahaya bagi kandungan saya }\end{array}$ & 5 & 27 & 18 & 27 & 13 & 254 & 56,44 & $\begin{array}{l}\text { Sedang } \\
\text { (Baik) }\end{array}$ \\
\hline $\begin{array}{l}\text { Saya memerlukan informasi mengenai } \\
\text { indeks obat-obatan kategori keamanan } \\
\text { pada kehamilan }\end{array}$ & 0 & 3 & 11 & 46 & 30 & 373 & 82,89 & $\begin{array}{c}\text { Tinggi } \\
\text { (Sangat Baik) }\end{array}$ \\
\hline $\begin{array}{l}\text { Saya merasa kesulitan membaca istilah } \\
\text { medis pada brosur obat }\end{array}$ & 0 & 15 & 22 & 46 & 7 & 315 & 70,00 & $\begin{array}{l}\text { Sedang } \\
\text { (Baik) }\end{array}$ \\
\hline $\begin{array}{l}\text { Saya membutuhkan bantuan untuk } \\
\text { membantu menjelaskan istilah medis yang } \\
\text { kurang saya pahami }\end{array}$ & 0 & 2 & 10 & 57 & 21 & 367 & 81,56 & $\begin{array}{c}\text { Tinggi } \\
\text { (Sangat Baik) }\end{array}$ \\
\hline Total & 39 & 264 & 219 & 412 & 146 & 3712 & 68,74 & $\begin{array}{l}\text { Sedang } \\
\text { (Baik) }\end{array}$ \\
\hline
\end{tabular}

\section{Kesimpulan}

Gambaran persepsi ibu hamil tentang keamanan obat yang digunakan selama masa kehamilan di UPT Puskesmas Puter Kota Bandung sudah dalam kategori sedang (baik). 


\section{Ucapan Terima Kasih}

Diucapkan terima kasih kepada UPT Puskesmas Puter Bandung dan Dinas Kesehatan Kota Bandung atas pemberian izin pada penelitian ini.

\section{Daftar Pustaka}

1. Depkes RI. 2006. Pedoman Pelayanan Farmasi untuk Ibu Hamil dan Menyusui. Depkes RI: Jakarta.

2. FDA. 2014. https://www.federalregister.gov/documents/2014/12/04/201428241/content-and-format-of-labeling-for-human-prescription-drug-and-biologicalproducts-requirements-for

3. Gedeon C., dan Koren, G. 2005. Designing Pregnancy Centered Medications: Drugs Which Do Not Cross the Human Placenta. doi:10.1016/j.placenta.2005.09.001

4. Abdushshofi, MF, Elvina R, dan Hersunaryati Y. 2016. Evaluasi Ketepatan Penggunaan Obat Ibu Hamil di Departemen Obstetri dan Ginekologi Rumah Sakit "X". Farmasains Vol. 3. No. 1, April 2016.

5. Mitchell AA, Gilboa SM, Werler MM, Kelley KE, Louik C, Hernandez-Diaz S. 2011. Medication use during pregnancy, with particular focus on prescription drugs: 1976-2008. Am J Obstet Gynecol 2011;205:51 e1-8.

6. Lupatteli A, Spigset O, Twigg MJ, Zagorodnikova K, Mardby AC,Moretti, ME, et al. 2014. Medication use in pregnancy: a cross-sectional, multinational web-based study. BMJ Open 2014; 4:e004365: doi:10.1136/bmjopen-2013-004365

7. Aprilia RM, dan Artini IGA. 2017. Gambaran Pola Pengobatan dan Tingkat Pengetahuan Mengenai Penggunaan Obat Selama Kehamilan di Puskesmas Denpasar Utara II Bali. E-Jurnal Medika. Vol 6. No. 7. Juli 2017. http://ojs.unud.ac.id/index.php/eum.

8. Norcahyanti, I., Pratama, A. N. W., dan Asfarina, H. 2018. Survei Tingkat Pengetahuan tentang Keamanan Penggunaan Obat pada lbu Menyusui di Puskesmas Sumbersari Kabupaten Jember. Pharmaceutical Journal of Indonesia. 2018. 3(2): 65-74.

9. Aljoher AM, Alsaeed MA, AlKhlfan MA, Almethen AW, Almukhaitah MA, Zareen H, et al. 2018. Pregnant Women Risk Perception of Medications and Natural Products Use During Pregnancy in Alahsa, Saudi Arabia. The Egyptian Journal of Hospital Medicine (January 2018) Vol. 70, page 13-20

10. Augusty F. 2006. Metode Penelitian Manajemen. Semarang: Badan Penerbit Universitas Diponegoro.

11. Bimo W. 2004. Pengantar Psikologi Umum. Jakarta. Andi.

12. Notoatmodjo S. 2007. Promosi Kesehatan dan IImu Perilaku. Jakarta. Rineka Cipta.

13. Nugraha MWD, 2009. Evaluasi Penggunaan Obat pada Masa Kehamilan Pasien Rawat Jalan di RSU Santa Elisabeth Purwokerto periode Oktober-Desember 2008. Skripsi. Universitas Sanata Dharma. Yogyakarta

14. Tronnes JN, Lupattelli A, Nordeng H. 2017. Safety profile of medication used during pregnancy: results of a multinational European study. Pharmacoepidemiology and Drug Safety. 2017; 26: 802-811 